\title{
IKAN PARI AIR TAWAR DAN SEJENISNYA SEBAGAI IKAN HIAS YANG POTENSIAL
}

\author{
Sudarto \\ Balai Riset Budidaya Ikan Hias \\ Jl. Perikanan No. 13, Pancoran Mas, Depok \\ E-mail: bukembar@yahoo.com
}

\begin{abstract}
ABSTRAK
Ikan pari air tawar Himantura signifer termasuk genus Himantura yang terdiri atas 40 spesies. Ikan ini banyak diburu orang untuk dijadikan ikan hias. Akibat perburuan tersebut maka ikan ini menjadi langka di beberapa habitatnya antara lain di Jambi, Kalimantan, dan Papua. Oleh karenaitu, diperlukan upaya untuk merehabilitasi habitat maupun po pulasinya di alam melalui restocking dan konservasi habitat. Uji coba pembiakan sedang dilakukan dan diharapkan keberhasilan pengembangbiakannya dapat memperbaiki populasi ikan ini di alam.
\end{abstract}

\section{KATA KUNCl: pari air tawar, ikan hias}

\section{PENDAHULUAN}

Penyebaran anggota famili Dasyatidae ini mulai dari Samudera Atlantik, Samudera Hindia, dan Pasifik. Utamanya hidup di laut tetapi dijumpai juga di perairan payau dan tawar. Sisi kepalanya menyatu dengan bagian tepi dari sirip dada. Bernafas dengan cara mendorong air melalui sebuah lubang kecil di belakang mata dan mengeluarkannya melalui celah insang di bagian bawah badan. Tak mempunyai sirip punggung, jika ada, juga tidak tampak. Bentuk badan menyerupai cakram yang garis lingkarnya sama dengan 1,2 kali panjangnya. Tak mempunyai sirip ekor. Ekornya panjang seperti cambuk atau cemeti. Kebanyakan spesies ikan ini mempunyai minimal 1 duri berbisa yang relatif panjang, yang dapat menyebabkan rasa sakit yang sangat luar biasa jika tersengat (Noga. 1995). Spesies terbesar mencapai lebar atau panjang sekitar $4 \mathrm{~m}$ yang hidup di laut. Reproduksi ikan ini dengan cara mengandung (ovoviviparous) dengan anak yang berkembang sempurna (Trygonidae). Saat ini di dalam perdagangan ikan hias telah diintroduksi berbagai jenis ikan pari yang harganya sangat mahal. Sebenarnya kitapun mempunyai potensi berbagai jenis ikan pari yang bisa dijadikan hias.
Famili Dasyatidae termasuk kelas Elasmobranchii dan ordo Rajiformes. Terdiri atas 9 genus dan 70 spesies (Schuster \& Djajadiredja, 1952; Kottelat et al., 1995). Beberapa jenis ikan ini diperdagangkan sebagai ikan hias seperti pari tawar (Suryanata, 2007). Dibandingkan jenis ikan lainnya maka golongan ikan pari aktivitasnya normal atau sama dengan ikan lainnya. Tercatat di dalam evolusi geologi bahwa anggota ikan pari sudah ada sejak jaman Cretaceous. Dijumpai dari $60^{\circ}$ lintang utara hingga $50^{\circ}$ lintang selatan dan $125^{\circ}$ bujur barat hingga $178^{\circ}$ bujur timur. Etymology famili ini dari bahasa Yunani: dasys sama dengan rambut.

\section{GENUS Himantura}

Genus Himantura terdiri atas 40 spesies yaitu: $\mathrm{H}$. uarnak, H. jenkinsii, H. uarnak, H. alcockii (Pale-Spot Whip Ray) H. bleekeri (Bleeker's Whipray) H. chaophraya (Freshwater Whipray) H. draco (Dragon Stingray) H. fai (Pink Whip Ray) H. undulata, H. fluviatilis (Ganges Stingray) $H$. gerradi, $H$. gerrardi (Banded Whiptail Ray) $H$. granulata (Macleay's Coachwhip Ray) H. imbricata (Scaly Stingray) $H$. jenkensii, $H$. jenkinsii (Brown Stingray) $H$. krempfi (Marbled Freshwater Whip Ray) H. margarita, $\mathrm{H}$. marginatus (Black-Edge Whip Ray) H. microphthalma (Smalleye Whip Ray) H. narnak, H. nudus, $H$. oxyrhyncha

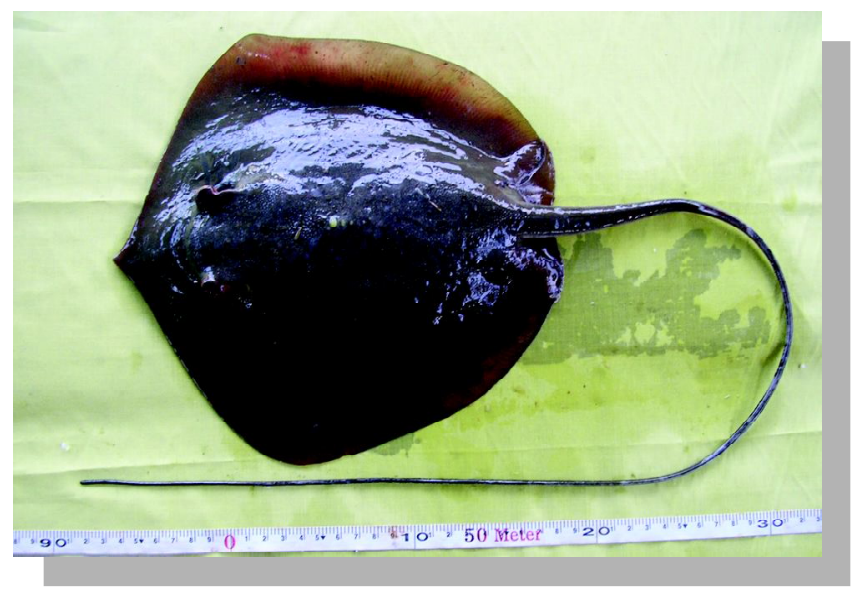

Gambar 1. Ikan pari air tawar, Himantura signifer (Roberts, 1989), yang diperjualbelikan sebagai ikan hias 
(Longnose Marbled Whip Ray) H. pacifica (Pacific Chupare) $H$. pareh, H. pastinacoides (Round Whip Ray) H. chaophraya, $H$. ponapenensis, $H$. schmardae (Caribbean Whiptail Stingray) H. signifer (Freshwater Stingray) H. toshi (Black-Spotted Whip Ray) H. uarnacoides (Bleeker's Whipray) H. uarnak (Banded Whiptail Stingray) H. undulata (Leopard Whip Ray) H. uranak, H. varnac, H. varnak, H. walga (Dwarf Whip Ray) H. warnak, H. imbricata.

Salah satu spesies yang sudah banyak dikenal yaitu ikan pari air tawar (Roberts, 1989) (Gambar 1).

Klasifikasi ikan pari air tawar di dalam taksonomi sebagai berikut:

- Domain : Eukaryota - eukaryotes

- Kingdom : Animalia-animals

- Subkingdom : Bilateria-bilaterians

- Branch : Deuterostomia-deuterostomes

- Infrakingdom : Chordonia

- Phylum : Chordata-chordates

- Subphylum : Vertebrata-vertebrates

- Infraphylum : Gnathostomata auct. - jawed vertebrates

- Class : Elasmobranchii-shark-like fishes

- Subclass : Elasmobranchii-shark-like fishes

- Infraclass : Euselachii

- Cohort : Neoselachii

- Superorder : Batoidea - rays

- Order : Rajiformes-skates and rays

- Family : Dasyatidae-stingrays

- Genus : Himantura - whip rays

- Specificname : Signifer

- Scientificname : Himantura signifer

\section{Sinonim:}

1. Dasyatis schmardae

2. Himantura schmarde

3. Trygon schmardae

Nama Inggris/nama dagang: White-Edge Freshwater Whip Ray, White-EdgeFreshwater Whipray, White-Rimmed Stingray.

Nama Indonesia/nama daerah: Ikan pari air tawar (Saanin, 1952).

Deskripsi morfologi: Ukuran maksimum mencapai diameter 31,2-60,0 cm. Panjang total bisa mencapai 200 $\mathrm{cm}$. Pita tipis putih melingkari badan, permukaan perut datar; klep spiral dengan 11-14 putaran. Pita tipis warna putih yang mengelilingi tubuhnya; titik-titik putih pada bagian di depan dan sekeliling mata. Bagian bawah badannya datar, klep spiral dengan 11-14 lingkaran. Panjang bagian tubuh tanpa ekor mencapai $60,0 \mathrm{~cm}$, sedangkan panjang totalnya bisa mencapai lebih dari $200 \mathrm{~cm}$ (Lagler et al., 1962).

Habitat dan perkembangbiakannya: Hidup di bagian benthopelagis perairan tawar, juga payau. Hidup di daerah estuarin atau sungai-sungai yang berdasar pasir. Makanannya adalah penghuni dasar yaitu udang-udangan dan kekerangan yang hidup di bagian dasar. Memijah di perairan tawar, bersifat ovovivipar. Menghuni dasar berpasir di daerah estuaria dan juga sungai. Berkembang biak di air tawar. Luka pada bagian tubuh manusia yang disebabkan oleh duri sirip punggung sangat membahayakan dan bisa menyebabkan kematian. Ikan ini dijual sebagai ikan konsumsi, tetapi saat ini diburu secara intensif untuk dijual sebagai ikan hias, sehingga populasinya di alam seperti di Jambi mengalami penurunan drastis dan sudah sangat sulit didapat. Untuk itu,

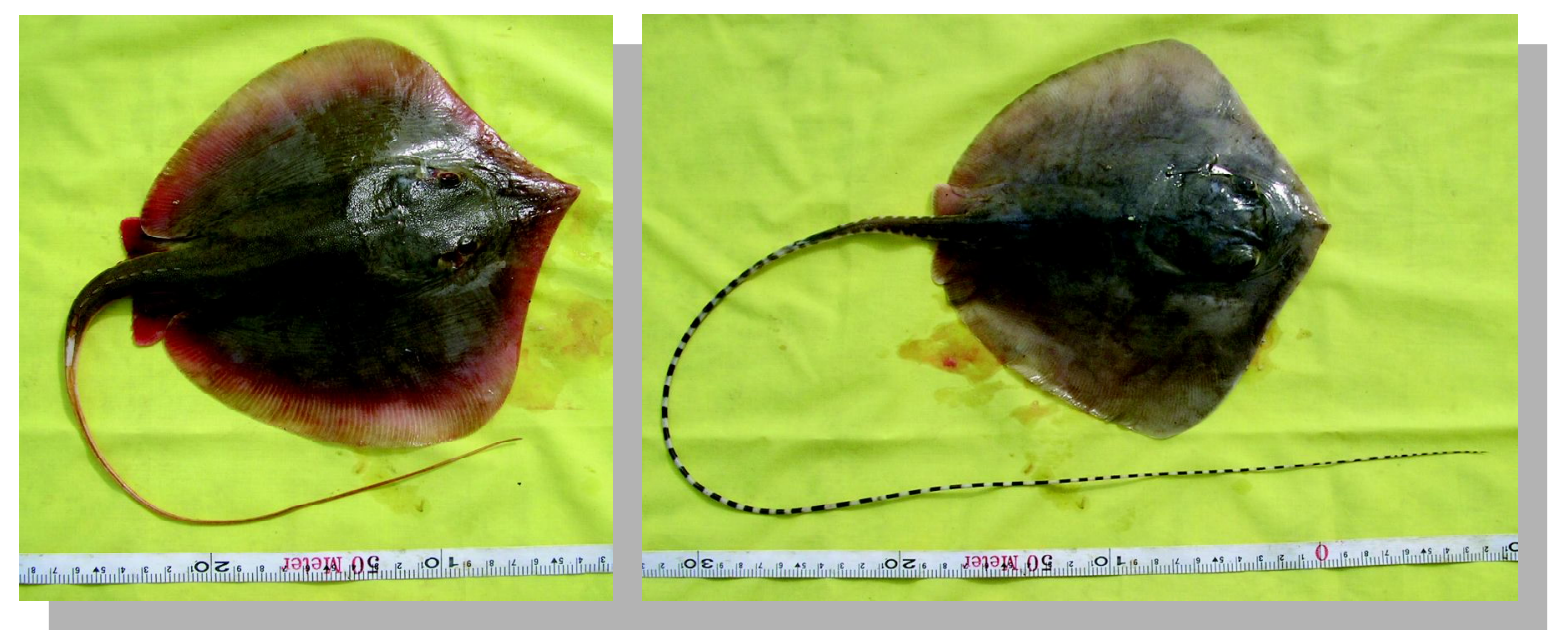

Gambar 2. Himantura imbricata (kiri) dan Dasyatis bennetti (kanan) yang berpotensi sebagai ikan hias 
diupayakan agar populasinya di alam harus dijaga melalui pengembangan eks situ di luar habitatnya dan melakukan restocking jika pengembangbiakannya telah berhasil dan melakukan konservasi habitat di mana ikan pari ini hidup.

Jenis lain yang banyak dijumpai di daerah estuaria atau muara sungai yaitu Himantura imbricata dan Dasyatis bennetti terlihat pada Gambar 2.

Daerah penyebaran: Sumatera, Kalimantan Barat (Indonesia) (Paysan, 1975), Malaysia dan Thailand (Chao Phraya, Mekong, dan Sungai Tapi).

Status pembudidayaannya/nilai ekonomi: Walaupun ikan ini ditangkap secara intensif dan ada kecenderungan mengalami degradasi populasi dengan indikator jumlah tangkapan yang jauh menurun, tetapi usaha budidaya belum dilakukan. Ikan ini ditangkap dari alam untuk dijual sebagai ikan hias, atau dijadikan ikan konsumsi.

Tingkat konservasi: Belum ada usaha konservasi dan statusnya terancam punah.

\section{KESIMPULAN}

Ikan pari air tawar (Himantura signifer) merupakan salah satu jenis ikan pari yang banyak diburu untuk dijadikan ikan hias, akibatnya terjadi penurunan populasi di alam dan diperlukan upaya pengembalian populasinya di alam melalui pengembang biakan eks situ dan restocking disertai konservasi habitatnya.

\section{DAFTAR ACUAN}

Kottelat, M., Whitten; A.J., Kartikasari; S.N., \& Wirjoatmodjo, S. 1995. Freshwater Fishes of Western Indonesia and Sulawesi.Periplus Edition (HK) Ltd. And Ministry of State for Population and Environtment. Rep. of Indonesia, 293 pp.

Lagler, K.F., Bardach, J.E., \& Miller, R.R. 1962. Ichthyology. John Wiley and Sons, Inc. New York, 545 pp.

Noga, E.J. 1995. Fish Disease Diagnosis and Treatment. Mosby-Year Book, Inc. Missouri.

Paysan, K. 1975. The country life guide to Aquarium Fishes. Country life books, 239 pp.

Roberts, T.R. 1989. The freshwater fishes of Western Borneo (Kalimantan barat, Indonesia). California Academy of Sciences. San Francisco, 210 pp.

Saanin, H. 1952. Kunci identifikasi ikan. Van Hoeve, Bandung, $200 \mathrm{hlm}$.

Schuster, W.H. \& Djajadiredja, R.R. 1952. Local common names of Indonesian fishes. N.V. Penerbit W. Van Hoeve. Bandung, 276. hlm.

Suryanata, L. 2007. Aquarium Aquascaping. Aquarista. Jakarta , $237 \mathrm{hlm}$. 